\title{
Editorial
}

Asian Business \& Management (2007) 6, 117-121. doi:10.1057/palgrave.abm.9200214

\section{Guest Editorial for Japan Society of Business Administration Special Edition} for ABM

Theme of the Special Edition:

Japanese Business and Society in a Global Age

With the dissolution of the Soviet Union in 1991 and the collapse of the socialist vs capitalist Cold War structure, the socialist economic model of business management as part of a planned economy lost its status as a platform for research in business administration studies, being replaced by the development of research into the market economy.

On the one hand, globalization in the market economy is seen as a process whereby marketable and efficient companies seek growth or survival through expanding cross-border business operations; at the same time, local lifestyles and social structures may converge towards an efficient market alongside the market economy. On the other hand, however, it is gradually becoming clearer that the arena of the market economy is one which, when the constituent details and systems themselves are considered, contains even more diversity than the differences between socialist and capitalist economies. It is also becoming clear that the development of business management within the market economy and the 'society' that surrounds it (community, lifestyles, customs, culture and laws) is something that is truly rich in its variety. We now live in an age where, when we look at the diversity of business management, market economy and society, we are able to see new horizons (or research challenges) in the field of business administration studies. It is my opinion that, from a Japanese perspective, the new research challenge is one of 'Japanese business and society in a global age'.

In the past, research into Japanese business has paid more attention to the 'uniqueness' or 'backwardness' of 'Japanese-style management' than to its international rationality. However, it goes without saying that business management not only possesses the particular characteristics of its nation or region, but also has an international aspect. Any justification for believing that Western business management is international and Japanese business management is 'backward' has disappeared as many Japanese enterprises are steadily increasing their influence overseas. 
However, this does not mean that phenomena such as the Toyota Production System or 'Japanese-style management' do not have a distinctiveness particular to Japanese society. It is especially important to note here that this distinctiveness can be divided into: (1) things that need to be gradually eliminated through the process of developing globalization (backwardness) and (2) things that can be seen as distinguishing and diversifying the system (sources of diversity). The Ford Production System and divisional organization at $\mathrm{Du}$ Pont and General Motors were created out of the 'traits that distinguish and diversify the system' that were particular to the United States of America. Later, when the Ford Production System was transferred to Japan, the 'traits that distinguish and diversify the system' that were created particular to Japan included the Toyota Production System and Toyota Way. In other words, new management systems do not arise as a result of the convergence of systems, but rather out of their local distinctiveness and diversity.

The aim of this special edition is to clarify what is needed to maintain a 'Japanese individuality' (uniqueness or distinctiveness) that can be the source of new systems through the process of globalization, at the same time as providing an understanding of the effects of globalization on Japanese business and society. The five papers presented here address these points by offering a perspective on the issues, and four articles deriving from that outlook.

The overall perspective is provided by Takao Nuki's paper on 'Environmental Issues and Theory of Management', which argues that we cannot afford to leave escalating global environmental problems down to the economic methodology of 'the internalisation of external diseconomies'. He stresses the need for an economic research methodology to tackle research into corporate standards for decision-making and corporate production systems, and presents a viewpoint prioritizing 'the greening of management' and the internalization of environmental measures. Firstly, he explains how in response to escalating environmental problems, social awareness of environmental issues has developed in five specific areas. He discusses the roles and limits of technological and economic countermeasures, and measures taken to foster environmentally conscious management at companies, such as corporate social responsibility (CSR), the manufacture of more durable products and eco-business. Such a new approach requires a longer-term perspective and plurality in decision-making principles, and he notes that, whatever the competitiveness of core industries in the Japanese industrial structure, weaknesses in so-called 'vein' processes and industry do not support its sustainability; as a result, Asia-led global economic growth may well lead to Asia-led global environmental crisis.

Nobuyuki Tokoro follows on from this perspective to look at the dynamically changing relationship between business and society through relationships between CSR and stakeholders, and analyses its specific traits. In the past, research on the relationship between companies and stakeholders was 
explained in terms of two traits, 'restrictions' and 'transactions'. However, new relationships that cannot be explained by these traits can now be seen as a result of a transformation in companies' relationship with society that has accompanied advances in the quality of business management and the rise of diverse stakeholders such as non-profit organizations. In other words, there has been a recently observed phenomenon of positive interaction by companies with their stakeholders to tackle social problems and attempts to increase competitiveness by discovering new perspectives on management as a result of that interaction. The paper describes this relationship in terms of 'value creation', and characterizes this as a new development. Western companies, where corporate social responsibility has already developed to some extent, have taken the lead in stakeholder interaction, and moves are being made in the West to standardize the interactive process in order to better understand, in an objective way, the strategic value of stakeholder dialogue. In Japan, on the other hand, voices can be heard questioning the effectiveness of such standardization. Tokoro employs the philosophy of Nonaka Ikujiro, an advocate of knowledge creation, to point out the need for a unique Japanese approach to understanding the strategic value of interaction, an approach that is distinct from the Western model, based on Nonaka's claims that 'varied innovation does not arise out of the process of objective theoretical analysis, but through the process of attempting to eliminate inconsistencies and conflict'.

Chiaki Nakano addresses 'The Significance and Limitations of Corporate Governance from the Perspective of Business Ethics', pointing out how phrases such as 'corporate governance', 'business ethics', 'compliance' and 'corporate social responsibility' have become primary sources of discourse in Japan in recent years. The direct catalyst for this was the sharp increase in corporate scandals that occurred after the bursting of the economic bubble in the early 1990s, but behind this also lies the serious environmental destruction that has occurred in the wake of economic activities related to both globalization and the information technology revolution, and the accompanying changes in society's expectations of companies. The validity of the Friedman-esque view that companies exist to optimize profits, and their only social responsibility lies towards shareholders' interests, is gradually eroding, even if we accept that a company is by definition a profit-seeking enterprise. Nakano outlines two coherent combinations of corporate governance systems with corporate ethics systems: (1) 'Shareholder-centred governance' and 'the establishment of compliance-style corporate ethics'; and (2) 'Corporate-conscience-based governance' and 'the establishment of corporate ethics with shared values'. $\mathrm{He}$ argues that the latter is more effective and that there is a need to work towards the establishment of an ethical organizational culture.

Park Tae-Hoon then investigates 'Reciprocal Mechanisms between the Hierarchical Division of Product Development Tasks and Organizational 
Relations' among Toyota suppliers. He notes how demands in the automotive industry for the simultaneous achievement of product differentiation and speedier development time are rising along with market segmentation and increasing global competition. As a result, product architecture strategies are being closely watched as a tool for achieving the above contemporary requirements of industry. However, in terms of research, the main focus has been on delay and investment strategies of car manufacturers and their primary parts makers, and there has not been sufficient investigation into how best to decide upon appropriate strategies for first-, second- and third-tier makers through collaboration between the respective companies. The paper expands the research subject to second- and third-tier suppliers and, working from the example of inter-organizational relations between different levels of suppliers for a power-steering development at Toyota Motor Corporation, reinvestigates the judgement criteria for how to decide upon delay or investment strategies. The inter-organizational relations at parts makers can be seen as 'integral type' at the top of the hierarchy, and rather more of a 'division of labour type' at the bottom. 'Speculative strategy' is adopted where 'division of labour type' interorganizational relations exist, and 'postponement strategy' where 'integral type' relations exist. The hierarchical division of labour composition in the automotive industry is identified as a major factor in influencing the decision as to whether to employ a postponement or speculative strategy. In other words, postponement or speculative strategies are decided according to a company's level in the hierarchical process in which parts supply in undertaken.

Finally, we have Narumi Tsukamoto, exploring the 'Social Consequences of Diversified Employment', who argues that the diversification of employment currently underway in Japan has resulted from corporate technological and economic needs during the spread of globalization and information technology, and has brought about two social consequences: the marketization and systematization of the public and social sector, and the social disintegration and restructuring of labour as a social entity. The systematization and penetration of market principles into the public and social sector over-rationalizes society, though simultaneously advancing individuation. Furthermore, diverse employment relations and flexible employment destroy employment security, and fragment working life and workers' cooperative relations within the workplace. The latter demands a social reorganization of the workforce, and to that end the performance-based personnel system is gradually taking hold in Japanese management. However, as this system essentially seeks to rationalize and discipline labour both technologically and economically, rather than to integrate society, it leads to excessively individualistic and impersonal social relations in the workplace and beyond; when individualism goes too far, civic voluntarism decays, and voluntary cooperation from the workforce declines. This way leads to a one-dimensional 
working society in which everyone is bound into the labour market and only waged activities hold social value. Employment diversification ushers market principles into the public and social sector; to counter such marketization, we need measures such as a social security system that does not work from market principles, the fostering of communities and a recognition of skills that do not necessarily meet market needs.

The theme of 'business and society' involves asking questions, from a social perspective, about what business or its administration entails. It is important to recognize the social nature of business, not only from the perspective of how far it is regulated, but also in terms of a complementary regulation of business and society that looks to the future direction of social development, in terms of history rather than stereotypes, and by seeing 'business and society' from the perspective of its relationship with the cultural uniqueness and diversity of regions and societies.

As editor of this special edition, I would like to thank the following people for their participation on the Editorial Advisory Council and Editorial Committee:

Koji Okubayashi, Setsunan University; Shinshi Kataoka, Momoyama Gakuin University; Kenichi Kuroda, Meiji University; Shunji Kobayashi, Waseda University; Takenori Saito, Yokohama City University; Yoshiji Suzuki, Doshisha University; Teruyoshi Tanaka, Ritsumeikan University; Keiji Natsume, Ryukoku University; Tsuyoshi Numagami, Hitotsubashi University; Kappei Hidaka, Chuo University; Makoto Fujita, Waseda University.

Masaki Hayashi Guest Editor, Chief Editor of JSBA Journal Chuo University, Tokyo 